\title{
Interactive behaviors and attachment patterns in the strange situation procedure: A validation of the Ainsworth model
}

\author{
Alessandra Simonelli", Francesca De Palo, Micol Parolin, Marilena Moretti \\ Department of Developmental and Socialization Psychology, University of Padua, Padova, Italy
}

Email address:

alessandra.simonelli@unipd.it (A. Simonelli)

\section{To cite this article:}

Alessandra Simonelli, Francesca De Palo, Micol Parolin, Marilena Moretti. Interactive Behaviors and Attachment Patterns in the Strange Situation Procedure: A Validation of the Ainsworth Model. Psychology and Behavioral Sciences. Vol. 3, No. 2, 2014, pp. 75-84. doi: $10.11648 /$ j.pbs.20140302.17

\begin{abstract}
The Strange Situation Procedure (SSP; Ainsworth, Blehar, Waters, Wall, 1978) is the most widely used procedure to assess attachment in early childhood (Bowlby, 1969). In the original text by Ainsworth et al. (1978), the video coding is carried out by means of a two-step procedure: in the first part, coders apply a series of observational scales with graduated scores on a Likert scale, whereas during the second part, a descriptive category of attachment is assigned, which somehow "summarizes" the general quality of the child's behaviour, already assessed by means of scales. Obviously, the system validation study highlights a discriminant correspondence between the scores which are assigned through the scales and the descriptive category which is assigned in the end. The aim of the present study was to test this specific aspect of the Strange Situation coding procedure: in order to do so, and similarly to what had been done in the original work in 1978, we compared the categorical attachment classification system with the ordinal one provided by the scales, which describe the child's behaviors in the various procedure episodes. 76 12-month-old infants were observed in the Strange Situation Procedure in order to compare the classification of attachment by the global descriptive patterns with the Ainsworth's microanalytic coding system (Interactive Behavior Scales). Results: Discriminant function analysis (MDFA) and classification weights confirm the discriminant functions of the interactive behavior to differentiate between patterns of attachment and attesting good validity of the methodology and the coding system.
\end{abstract}

Keywords: Strange Situation Procedure, Interactive Behavior Scales, Discriminant Analysis, Patterns of Attachment

The Strange Situation Procedure (SSP; Ainsworth, Blehar, Waters, Wall, 1978) is the most widely used procedure to assess attachment in early childhood (Bowlby, 1968, 1973, 1980). Indeed, this method finds very large application in many fields of research: suffice it to say that if you enter SPP as your search keyword in the psycINFO database and select a time interval ranging from 1967 (the publication year of Ainsworth's Infancy in Uganda) till April 2010, you will get 827 international research papers which describe the application of this methodology. The number of papers focusing on the SSP have increased in the time, even without taking into account the papers which have been published in journals that are not indexed and cannot, therefore, be found through a database research. They would surely provide for an even more comprehensive list than the one we have in our hands which, in fact, already is a very remarkable one (Graph 1).

However, most of these research studies reveal their limits in the applied coding system. In fact, in the original text by Ainsworth et al. (1978), the video coding is carried out by means of a two-step procedure: during the first part of the procedure, coders apply a series of observational scales with graduated scores on a Likert scale, whereas during the second part, a descriptive category of attachment is assigned, which somehow "summarizes" the general quality of the child's behaviour, already assessed by means of scales. Obviously, the system validation study highlights a discriminant correspondence between the scores which are assigned through the scales and the descriptive category which is assigned at the end. As a matter of fact, in all subsequent literature, observational scales are not quoted, nor are they used: categories are assigned without putting the scales to the test, nor are they checked for reliability when confronted with possible theoretical, cultural and training changes, which research and researchers in this field so often undergo. 
The aim of the present study was to test this specific aspect of the Strange Situation coding procedure: in order to do so, and similarly to what had been done in the original work in 1978, we compared the categorical attachment classification system with the ordinal one provided by the scales, which describe the child's behaviors in the various procedure episodes.

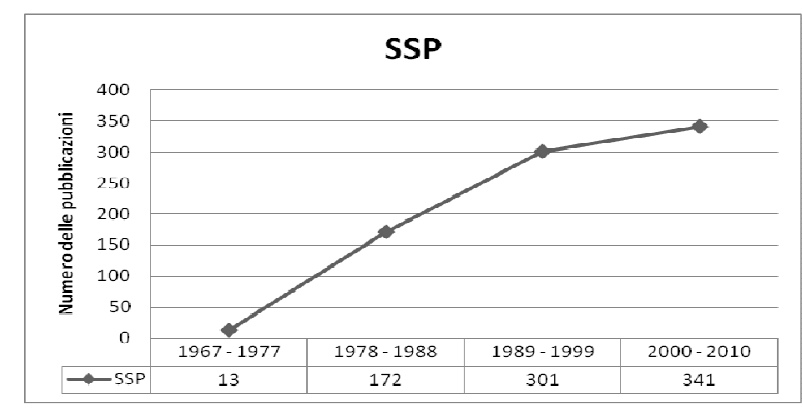

(Database: psycINFO, time interval $(1967-2010)$

Numero delle pubblicazioni $=$ Number of papers

Graph 1. Use of the Strange Situation Procedure - Trend over Time.

\section{The Strange Situation Procedure}

The Strange Situation is a standardized observation procedure (Ainsworth, et al., 1978; Ainsworth, Wittig, 1969) which aims at activating and intensifying the child's attachment behavior towards his/her parent by exposing the child to a moderately, yet increasingly stressful situation. In fact, the Strange Situation takes place within a context - an observation laboratory - which is not familiar to the child: it foresees the presence of an unfamiliar adult and a series of two separations and reunions with the mother (or any other adult figure we might be interested in studying the child's attachment relationship with). This procedure is applicable to children between 12 and 24 months of age: between two subsequent administrations, a time interval of at least 6 months must be respected, so that the child can forget the situation and the stressful feelings tied with it (Ainsworth, 1985; Ainsworth, Bell, Stayton, 1971).

The procedure is subdivided into eight short episodes, each of them lasting approximately three minutes and following one another according to a fixed order and a clearly stated consignment (Scheme 1).

Scheme 1. The Strange Situation episodes (adapted from Ainsworth et al., 1978).

\begin{tabular}{|c|c|c|c|}
\hline $\begin{array}{l}\text { Episode } \\
\text { number }\end{array}$ & Participants & Length & Short description \\
\hline 1 & $\begin{array}{l}\text { Mother, infant and } \\
\text { observer }\end{array}$ & $30 \mathrm{sec}$ & $\begin{array}{l}\text { The observer introduces mother and infant into the room, then he/she leaves the } \\
\text { room }\end{array}$ \\
\hline 2 & $\begin{array}{l}\text { Mother and } \\
\text { infant }\end{array}$ & $3 \mathrm{~min}$. & $\begin{array}{l}\text { Mother does not participate while infant explores. If necessary, play activities } \\
\text { are encouraged after } 2 \text { minutes. }\end{array}$ \\
\hline 3 & $\begin{array}{l}\text { Mother, infant and } \\
\text { stranger }\end{array}$ & $3 \mathrm{~min}$. & $\begin{array}{l}\text { Stranger enters. First minute: stranger is silent. Second minute: stranger } \\
\text { converses with the mother. Third minute: stranger approaches infant. After } 3 \\
\text { minutes, mother leaves unobtrusively. }\end{array}$ \\
\hline 4 & Infant and stranger & $3 \mathrm{~min}$. or less & First separation episode. Stranger's behavior is adjusted to that of infant. \\
\hline 5 & Mother and infant & 3 min. or more & $\begin{array}{l}\text { First reunion episode. Mother greets and/or comforts infant, then tries to engage } \\
\text { him/her in play. Mother leaves again, saying "bye-bye". }\end{array}$ \\
\hline 6 & Infant alone & 3 min. or less & Second separation episode. \\
\hline 7 & Infant and stranger & $3 \mathrm{~min}$. or less & $\begin{array}{l}\text { Continuation of second separation episode. Stranger enters and adjusts behavior } \\
\text { to that of infant. }\end{array}$ \\
\hline 8 & Mother and infant & 3 min. or more & $\begin{array}{l}\text { Second reunion episode: mother greets infant, picks him/her up and comforts } \\
\text { him/her, then tries to engage him/her in play. }\end{array}$ \\
\hline
\end{tabular}

The SSP coding is based on the observation of the overall organization of a child's attachment behavior and foresees two assessment levels: the first one is based on graduated ordinal scales on a 7-point Likert scale (range 1 7), which refer to specific behavioral sequences the child can display in the various episodes. They can be applied to each procedure episode at 15-second intervals (Scheme 2).

\section{Scheme 2. Assessment scales of interactive behaviors in the Strange Situation Procedure (Ainsworth et al., 1978)}

Proximity and contact seeking: refers to behaviors by means of which the infant seeks physical contact with his/her caregiver or else, simple proximity, as well as to the degree of intensity and persistence with which these behaviors are shown (It is applied to episodes 2, 3, 5 and 8 to assess interactive behaviors towards the mother and to episodes 3, 4 and 7 to assess interactive behaviours towards the stranger).

Contact maintaining: refers to behaviors by means of which the infant attempts at resisting against being left and maintaining physical contact with the adult, once contact has been established (It is applied to episodes 2, 3, 5 and 8 to assess interactive behaviors towards the mother and to episodes 3, 4 and 7 to assess interactive behaviors towards the stranger).

Resistance: refers to those opposition behaviours which show a certain degree of rage, irritation and aggressiveness. Usually, these behavioral attitudes emerge in response to the adult's attempts to get in touch or interact with the infant after the separation episodes: these attitudes can be addressed towards the adult, or else, towards the toys or any other object in the room (It is applied to episodes 2, 3, 5 and 8 to assess interactive behaviours towards the mother and to episodes 3, 4 and 7 to assess interactive behaviours towards the stranger). 
Avoidance: refers to those behaviors which testify to the infant's attempt to ignore the adult or avoid any kind of interaction with him/her, even at a distance. When the adult tries to establish a relationship with the infant or engage $\mathrm{him} / \mathrm{her}$ in play, or else, during a reunion episode, the infant walks away, turns his/her head away, looks away, turns his/her back on the adult, hides his/her face or simply carries on with his/her activities, ignoring all outside stimuli (It is applied to episodes 2, 3, 5 and 8 to assess interactive behaviors towards the mother and to episodes 3 , 4 and 7 to assess interactive behaviors towards the stranger).

Search attitude during separation episodes: refers to those behaviors by means of which the infant looks around for his/her caregiver, when the latter is not present in the room. Some of these behaviors can be more direct and clearer, such as walking towards the door, trying to open it or standing close to it most of the time. Others are weaker and less complete, such as looking at the door, walking towards the door without reaching it, looking at the chair or at mother's bag (It is applied to episodes 4, 6, 7 to assess behavior towards the mother; it is not applied to the interaction with the stranger).

Distance interaction: refers to positive, social and communicative behaviors (smiling, vocalizing, showing or offering a toy, pointing at specific objects inside the room) which clearly show that the child wants to interact with the adult and wants to share exploration, play or his/her inner states with him/her, even though he/she does not need close physical contact (It is applied to episodes 2, 3, 5 and 8 to assess interactive behaviors towards the mother and to episodes 3, 4, 7 to assess interactive behaviors towards the stranger).

The second level leads to the assignment of an attachment pattern according to four categories. It is based on the observation of the way in which the behavioral systems of attachment and exploration are organized during the whole procedure both towards the caregiver, as well as the stranger, while various stress elements are introduced, one after the other. The four categories are (Main, Solomon, 1986, 1990; Scheme 3): secure attachment (B) - research studies referring to "non-clinical" United States children show that between $54.9 \%$ and $67 \%$ of the population fall into this category; avoidant attachment (A) is observed in an average range of $20.5 \%-22.9 \%$ of the population. Resistant attachment (C) is less frequent among the population $(7.5 \%-12.5 \%)$, while disorganized/disoriented attachment (D) is observed in $14.7 \%$ of the children (van IJzendoorn, Goldberg, Kroonenberg, Frenkel, 1992).

\section{Scheme 3. Attachment categories in infancy (Ainsworth et al., 1978; Main, Solomon, 1986, 1990)}

Secure Attachment (B): describes an infant who seeks proximity, physical contact or interaction with the caregiver. When the latter is present, the infant engages in autonomous exploration of the environment but, usually, he/she actively encourages participation of the adult.
During the separation episodes, the infant clearly looks around for the adult, shows signs of stress and uneasiness which are tied to the absence of the caregiver and not to the fact that he/she has been left alone. During the reunion episodes, a secure infant displays his/her attachment towards the parent, greets him/her, seeks proximity or interaction or else, if he/she feels uneasy, he/she will seek physical contact and consolation. On the whole, when his/her caregiver returns after separation, the infant looks comforted and in fact, he/she resumes exploring the environment and the toys, displaying a typical secure base behavior.

Insecure Avoidant Attachment (A): infant clearly assumes an avoidant attitude towards his/her parent, especially during the reunion episodes. These infants appear particularly autonomous and independent, more focused on the exploration of the environment and the toys than on the presence of their caregiver. Usually, during separations, they scarcely show signs of uneasiness, they rarely look around for the adult and, during the reunion episodes, they seem to ignore or attach little importance to the fact that their caregiver is back. They tend to minimize their affective reactions, particularly after separations, and appear very busy and engaged in play. More generally, infants with insecure avoidant attachment show an unbalance between the exploration of the environment and the available toys, and attachment expressions towards their caregiver, with a preference for the first activity: with respect to their caregiver, they appear very independent, autonomous, and affectively self-sufficient. In other words, these children's distinctive feature is a tendency not to display their needs for protection, while emphasizing an autonomous and independent relational style.

Insecure Resistant/Ambivalent Attachment (C): describes infants who tend to be focused on the relationship with the adult rather than on exploration: they show little ability to explore the environment autonomously and to interact with the stranger, feel very uneasy during separation, and are difficult to comfort during reunion. In fact, even once the parent is back after separation, they do not look comforted: on the contrary, they show ambivalence on reunion and alternate and mix requests for proximity and contact with clearly resistant and extremely passive behaviors. More generally, these children display an unbalance between exploration and attachment, with a preference for the latter: the parent is not seen as a secure base, since he/she does not seem to be able to comfort the infant with his/her presence. The infant appears dependent and focused on his/her parent, with little autonomy and a tendency to show clear signs of attachment, characterized by rage or passivity, which are difficult to soothe.

Disorganized/Disoriented Attachment (D): is contradiction in some observed movements, which makes us think of an underlying contradiction in the infant's intentions or behavioral plans (disorganization) or else, a feeling that the little one has lost orientation in the environment which surrounds him/her (disorientation). 
These children's behavior is at times very confused, because they are not able to organize the situation efficiently, orientate behavior and affection, also because they assume clearly frightened and rigid attitudes both physically and through their face expressions. The most relevant aspect is that their disoriented/disorganized behavior appears only when the caregiver is present, especially during the reunion episodes.

The SSP original validation study highlights a direct correspondence between the children's scores at the scales of interactive behaviors and the assignment of a general attachment category: in other words, a discriminant analysis applied to the scores of the interactive scales leads to a distinction in 3 attachment patterns, as globally defined (Ainsworth et al., 1978). This statistical matching bears evidence of convergent validity between the two attachment classification systems within the SSP, so that the assessments obtained with the two systems do not show any significant difference. With the passing of time, this result has led to the almost exclusive use of the categorical method, which is considered more economical for the coder and, at the same time, equally reliable.

Especially during the first years after its publication, the Strange Situation Procedure was used in a very comprehensive series of research studies which aimed at verifying its characteristics of validity and reliability (Solomon, George, 2002).

As regards the construct validity, the theory foresees that the quality of a child's attachment is the outcome of the type of relationship which parents and children have built during the first year of a child's life: specifically, an adult's sensitivity and responsiveness towards a child's protection needs should be associated with secure attachment (B) at 12 months, while a caregiving style which is not adequately sensitive and responsive should be at the roots of an insecure type of attachment. In this respect, the investigation was focused on maternal characteristics and offered evidence of how secure children's (B) mothers showed greater engagement in the relationship, responsiveness to their children's emotional and verbal signals (Belsky, Rovine, Taylor, 1984), adequate levels of responsiveness (Smith, Pederson, 1988), as well as higher levels of affective contact and a more positive affective quality (Belsky, Isabella, 1991; Isabella, 1993). Two meta-analyses on the data available in the literature (Goldsmith, Alansky, 1987; DeWolff, van IJzendoorn, 1997) show clear empirical evidence of a correlation between maternal sensitivity and attachment security, in spite of contradictory data from other research studies (Schneider-Rosen, Rothbaum, 1993; Seifer, Shiller, Sameroff, Resnik, Riordan, 1996). Moreover, the association between paternal sensitivity and attachment quality in the father-child dyad is statistically and significantly weaker than in the mother-child dyad: this datum seems to weaken the theoretical significance of the construct which the Strange Situation is founded upon (DeWolff, van IJzendoorn, 1997). Finally, a series of cross-cultural research studies referring to the African,
Chinese, Japanese and Israeli culture show how the association between sensitivity and attachment is broadly documented. The authors are, therefore, led to interpret these studies as further evidence for the existence of this relation, even if sensitivity does not offer a unique and comprehensive explanation of individual differences in attachment (van IJzendoorn, Bakermans-Kranenburg, 2005; van IJzendoorn, Sagi, 2002). Subsequently, we aimed at verifying the Strange Situation's predictive validity with special reference to identifying any existing relationship between the quality of attachment - more specifically, secure attachment (B) - and the child's adjustment, since a feeling of security should work as an affective basis which favors the child's development. In this respect, reviews by Thompson (2002) and Weinfield, Sroufe, Egeland and Carlson (2002) point out how children with secure attachment at 12 months show greater social competences in the interaction with their peers and an ability to establish relationships with familiar and unfamiliar adults. Moreover, they show greater ability in affect regulation, particularly as regards negative emotions and aggressiveness; symbolic play lasts longer in these children and is more complex, and exploration sessions last longer too. Finally, these children show higher and more elaborate levels of cognitive and linguistic development (Meins, 1997; Bakermnas-Kranenburg, van IJzendoorn, 1993; van IJzendoorn, Dijkstra, Bus, 1995; Weinfield, et al., 2002). On the whole, the gathered data support the predictive value of attachment quality - as measured with the Strange Situation Procedure at 12 months - with reference to the child's development in various developmental domains, not only during the first years of life, but well into his/her preschool and school years.

As for instrument reliability, our first aim was to verify accordance among coders: the accordance rate among expert judges tends to be very high within groups of researchers who work together, varying from the $100 \%$ accordance rate in the original study by Ainsworth et al. (1978) to $85-95 \%$ in the studies by Main and Weston (1981) and by Waters (1979), who were trained by the procedure's author herself. However, studies comparing accordance rates between judges belonging to the same group and judges of other groups also found good reliability levels for the coding procedure, varying from $80 \%$ to $88 \%$ (see Solomon, George, 2002). The test-retest reliability within a 6-month interval was quite high - ranging from 50\% to $92 \%$ - but not homogeneous, probably because of events and conditions which can cause variations in the attachment style developed by the child (see Solomon, George, 2002).

\section{The Research}

In the light of what has been said, and taking the start from the studies on the Strange Situation Procedure available in the literature, the present research aims at offering an explorative study which was set out to reply and further verify some of the methodological and cross-cultural aspects of this procedure: specifically, those aspects which are currently considered as "hot" themes both for its application as well as for the study of 
attachment in infancy. Specific goal of this research were to use the quantitative coding scales of interactive behaviors within the SSP according to Ainsworth et al. (1978)' original system, so as to verify their psychometric properties and their discriminant value when it comes to identifying the descriptive categories of attachment. Ainsworth et al. (1978)' original study actually confirms the scales' discriminant validity with regard to the assigned attachment pattern (in other words, different scores assigned to the child's behavior by means of the a.m. scales identify the general attachment pattern which would be assigned if the procedure was blind-coded, without using the scales). This result offers a fundamental support to the methodological "validity" of the codifying systems: in fact, it strengthens the attachment assessment procedure by means of descriptive patterns while letting the application of the coding scales of behavior fall into oblivion. In this respect, our research aimed at replicating Ainsworth et al.' original study (1978), so as to test over time the validity of the two models assessing attachment in infancy, as well as to revive their parallel use.

\subsection{Participants}

The research was carried out on a group of 76 mother-child dyads. The recruited mothers belonged to a more comprehensive research project on parenthood transition which was put into place at the II Obstetrical Clinic of the Padua Civic Hospital. While attending childbirth classes at their $7^{\text {th }}$ month of pregnancy, they voluntarily joined the research. These mothers were contacted again when their children were 12 months of age: they agreed to take part to this data acquisition phase. Therefore, we can say that this was a self-selected group.

At the time of administration, children - 33 baby girls (43.3\%) e 43 baby boys (56.6\%) - were between 11 and 14 months of age (mean age $=12$ months and 24 days, $\mathrm{SD}=19.55$ days). The mothers' age ranged from 26 to 42 years (mean age $=33$ years, $\mathrm{SD}=3.76$ ), while the fathers' age ranged from 28 to 42 years (mean age $=33.01$ years, $S D=4.44$ ). As for their educational level, $58.3 \%$ of the mothers had a University degree, $40.3 \%$ had a high school degree, the remaining $1.4 \%$ had completed the first level of secondary school. Concerning their profession, $48 \%$ of our subjects were employees, $13.3 \%$ worked as professionals, while the remaining $38.7 \%$ either did not work, or else were employed on a part-time basis.

\subsection{Data Collection and Coding}

Data collection took place in the laboratories of the Department of Developmental and Socialization Psychology at the University of Padua, where dyads were administered the Strange Situation Procedure (SSP, Ainsworth, Wittig, 1969; Ainsworth et al., 1978): all procedures were videotaped and coded by 6 independent judges who had received appropriate training ${ }^{1}$. After

\footnotetext{
17 independent judges were appointed for the research. One of them (a trained judge) had been trained to code the Strange Situation by Prof. Sroufe at the Child Development Institute of Minneapolis, University of Minnesota, whereas
}

having completed their training, the 6 judges were randomly split in pairs: 2 pairs coded 50 SSP each, whereas 1 pair coded 52 procedures. Videos were subdivided into 3 groups: group 1 and 2 ( $25 \mathrm{SSP}$ ), group 3 (26 SSP). Each pair of judges was given a set number of procedures to code, according to the following scheme: the first pair of judges coded the SSP group 1 according to the pattern method, whereas they were asked to codify the SSP group 2 according to the system of interactive behaviors; the second pair of judges coded the SSP group 2 according to the pattern method and the SSP group 3 according to the system of interactive behaviors; the third pair of judges coded the SSP group 3 according to the pattern method and the SSP group 1 according to the system of interactive behaviors. In this way, no video clip was coded by the same pair of judges by applying the two (different) methods at the same time, so as to prevent any possible bias or mistake during the coding procedure.

Each video clip was classified according to one of the four attachment categories (see Scheme 3): secure (B), avoidant (A), resistant (C), disorganized/disoriented (D; Simonelli, De Palo, Moretti, Merlin Baratter, Porreca, 2014). Judges reached a mean concordance of $80 \%$ (K $=.74)$. At the same time, all SSPs were coded by means of the six scales of interactive behaviors (Ainsworth et al., 1978): while the original coding required assessment of the six interactive variables every 15 seconds, in the present research assessment refers to each single episode (3 minutes). Each scale was applied to episodes 2, 3, 5 and 8 to assess the child's interactive behaviors towards the mother, whereas each scale was applied to episodes 3, 4 and 7 to assess the child's interactive behaviors towards the stranger (see scheme 2). Through these scales, each procedure episode is assigned a score on a 7-point Likert scale (range $1-7$ ). The scores assigned to each single episode are then summed up, so as to obtain a global score for each scale. In brief, the scales referring to the child's interactive behaviors towards the mother will feature a global score varying from 4 to 28 points (each scale score ranging from 1 to 7, 4 single episode scores having to be summed up), whereas scales referring to the child's interactive behaviors towards the stranger will feature a global score varying from 3 to 21 points (each scale score ranging from 1 to 7, 3 single episode scores having to be summed up). Concordance calculated with the Interclass Correlation Coefficient (ICC) reached .988.

a second one (an expert judge) was an expert in assessing attachment and had completed a coding training with Prof. Crittenden (Department of Developmental and Socialization Psychology, University of Padua). The remaining 5 judges were formed and trained by the first two ones: more specifically, judges in training coded 30 videos and tested the reliability of their coding with the expert judge. Since the obtained concordance index reached a value of ICC $=.945$, the 5 judges in training were reputed to be able to proceed with data coding, while the expert judge was asked for advice for difficult SSP coding cases only. In brief, the coding procedure was carried out by 6 judges: 5 judges in training and 1 trained judge. 


\section{Results}

The goal of this study was to use the coding scales of interactive behaviors in the SSP according to the original system by Ainsworth et al. (1978), so as to test their psychometric properties and their discriminant value when it comes to identifying the descriptive categories of attachment. Table 1 includes the descriptive statistics, the correlations and the Cronbach's Alpha indexes. The Alpha index were calculated for each observational scale of interactive behaviors in the SSP, referring both to the mother-child interaction, as well as to the stranger-child interaction.

Table 1. Psychometrics properties of interactive scales.

\begin{tabular}{|c|c|c|c|c|c|c|c|c|c|c|c|c|}
\hline & $\mathbf{N}$ & Min & Max & Mean & SD & $\begin{array}{l}\text { a } \\
\text { mother }\end{array}$ & $\begin{array}{l}\alpha \\
\text { stranger }\end{array}$ & 2 & 3 & 4 & 5 & 6 \\
\hline $\begin{array}{l}\text { 1. Proximity and } \\
\text { contact seeking }\end{array}$ & 76 & 1.00 & 6.00 & 2.43 & 1.10 & .58 & .35 & $\begin{array}{l}.743 \\
*\end{array}$ & .054 &.$-437 *$ & $.471 *$ & -.146 \\
\hline $\begin{array}{l}\text { 2. Contact } \\
\text { maintaining }\end{array}$ & 76 & 1.00 & 6.00 & 1.96 & 1.09 & .69 & .34 & & $-.285^{*}$ & $-.359 *$ & $.524-$ & -.137 \\
\hline $\begin{array}{l}3 . \\
\text { Opposition/Resistance }\end{array}$ & 76 & 1.00 & 4.00 & 1.38 & .51 & .64 & .54 & & & -.081 & .102 & $-404 *$ \\
\hline $\begin{array}{l}\text { 5. Search attitude } \\
\text { diring separations }\end{array}$ & 76 & 1.00 & 7.00 & 3.37 & 1.60 & .73 & - & & & & - & .011 \\
\hline 6. Distance interaction & 76 & 1.00 & 6.00 & 2.02 & 1.02 & .74 & .63 & & & & & \\
\hline
\end{tabular}

$* \mathrm{p}<.01$

It can easily be noticed that all scales assessing mother-child interaction during the procedure show acceptable reliability indexes, whereas those assessing child-stranger interaction only show poor reliability, their indexes scoring less than .60: this is the reason why the latter were excluded from any further analysis.

In order to test whether the scores on the various scales of interactive behaviors during the procedure featured a normal distribution, we applied the Kolmogorov-Smirnov Test. It was possible to observe that only three out of six scales had a normal distribution, that is, the "Contact seeking" scale $(\mathrm{Z}=$ $1.075, p=.199)$, the "Avoidance" scale $(Z=.992, p=.279)$, and the "Search during separation" scale $(Z=1.154, \mathrm{p}=.140)$. On the contrary, the following scales: "Contact maintaining" $(\mathrm{Z}=1.832, \mathrm{p}=.002)$, "Opposition" $(\mathrm{Z}=1.959, \mathrm{p}=.001)$ and "Distance interaction" $(Z=1.388, p=.043)$ feature a distribution which is not superimposable to a normal one.

Tables 3 show, also, the descriptive statistics, which were calculated on the means of the scales of mother-child interactive behaviors and assessed for each SSP episode, and their correlations, which were calculated with the Spearman's method. The choice of a non-parametric method derives from the fact that some of the applied scales do not feature a normal distribution: consequently, a non-parametric approach to data analysis seemed to be more convenient. It can easily be noticed that the various scales correlate one with the other, which is in line with the theoretical hypotheses underlying the observation contents: therefore, scales assessing attitudes such as seeking contact and maintaining contact, both in the parent's presence and absence, show a positive correlation between them. On the contrary, they show a negative correlation with the avoidance and opposition attitudes.

Following the Ainsworth model (1978), the next step was to test correspondence between the criteria of pattern classification and score differences in the interactive behaviors of children making up the group of the present study.
Correspondence was tested by means of discriminant analysis. This statistical procedure has got two main goals: a descriptive one, which makes it possible to identify the variables which better contribute to differentiate two or more preformed groups of subjects, and a predictive one, which makes it possible to classify new cases by using information deriving from the analysis itself.

First of all, we carried out a univariate Analysis of Variance (ANOVA) so as to compare the means of interactive behaviors which had been assessed for each procedure episode and identify the presence of significantly different means within the three identified groups of attachment patterns. Then, according to this method, variables which were not significant in determining a distinction between the patterns were eliminated. Table 2 shows the mean values of the variables, subdivided by patterns (alpha $=0.016$, Bonferroni correction).

Table 2. Univariate ANOVA on the scores of interactive scales referring to each single episode.

\begin{tabular}{llllll}
\hline \multirow{2}{*}{ Variables } & \multicolumn{5}{l}{ Means } \\
& s & A & B & C & F \\
\hline Seeking contact & 5 & 1.59 & 3.18 & 2.64 & 7.755 \\
with Mother & 8 & 1.96 & 4.03 & 3.36 & 11.828 \\
Maintaining contact & 5 & 1.22 & 2.37 & 3.45 & 8.949 \\
with M & 8 & 1.67 & 2.95 & 3.82 & 6.823 \\
Resistance towards & 5 & 1.59 & 1.39 & 2.27 & 3.541 \\
M & 8 & 2.00 & 1.53 & 3.27 & 9.572 \\
Avoidance towards & 5 & 4.11 & 2.39 & 2.00 & 12.336 \\
M & 8 & 3.89 & 2.00 & 1.64 & 24.783 \\
Search M during & 7 & 1.78 & 3.37 & 3.09 & 5.619 \\
separations & & & & & \\
Distance interaction & 5 & 2.07 & 2.71 & 1.00 & 6.717 \\
with M & 5 & & & & \\
\hline
\end{tabular}

$* \mathrm{p}<.016$ Bonferroni correction 
It can be observed that F significance values (Table 2) show how the mean values referring to children with different attachment patterns differ significantly, mostly in episodes 5 and 8 of the procedure. In fact, if we compare the mean values of interactive behaviors, at least two out of three groups differ significantly. The following differences come to light: (a) compared with children with an avoidant attachment (A), children with secure attachment (B) seek contact more frequently and try to maintain contact more frequently during episodes 5 and 8, and they also look for their caregiver more frequently during episode 7 (second separation). Moreover, children with secure attachment (B) more frequently interact with their mothers at a distance during episode 5, something which differentiates them from children with resistant attachment (C); (b) compared with the other two groups, children with avoidant attachment (A) more frequently show an avoidant attitude towards their mothers during episodes 5 and 8; (c) compared with the other two groups, children with resistant attachment (C) more frequently show a resistant behavior and, compared with children with avoidant behavior (A), a more frequent tendency towards physical contact with their mothers during episodes 5 and 8 .

In the light of the results obtained through an Analysis of Variance (ANOVA), it was possible to reduce the number of variables we wanted to take into account and actually use only the ones which could help us to distinguish two or more children groups with different patterns. In fact, a discriminant analysis was applied using only the variables which had proved to be significant in the ANOVA. Table 3 shows the values of the significance test of discriminant functions, as supplied by Wilks' $\Lambda$ index.

The table shows the significant Lambda coefficients, associated with the two discriminant functions which can be identified through the data. These values allow us to say that both functions contribute to explain part of the differences between the groups. Moreover, in order to assess significance of each discriminant function, while referring to the proportion accounted for by the introduction of each function, it is possible to use the self-values of the matrix, the variance percentage which is accounted for by each function and the canonical correlation. The first function is the one that explains the highest degree of variance: in our case, $62 \%$ of the difference between groups derives from the first function, whereas $38 \%$ of the difference derives from the second one. As highlighted in the table, as far as canonical correlations are concerned, functions show good correlations with the groups. One further important aspect - also shown in Table 3 - is represented by the centroid values of the three groups. It can easily be noticed that the first group (avoidant attachment), when compared with the other groups, is characterized by higher values in the first function, whereas the third group (resistant attachment) features lower values than the other groups in the second discriminant function. Therefore, we can state that the first function mainly defines the group of subjects who are assigned an avoidant attachment pattern (A), and that it differentiates this group from the other two, whereas the second function defines a group of subjects who are assigned a resistant attachment pattern (C), differentiating it from the other two groups.

Tables 4 and 5 respectively show the contribution offered by each single variable within each discriminant function through the standardized coefficients and the discriminant structure coefficients.

Table 3. Discriminant function analysis.

\begin{tabular}{lll}
\hline & Function I & Function II \\
\hline Eigenvalues & 1.023 & .630 \\
Canonical correlation & .711 & .622 \\
Wilks' Lambda & .303 & .613 \\
\% Variance & 61.9 & 38.1 \\
Group barycentres & & \\
A & 1.322 & .151 \\
$\mathrm{~B}$ & -.824 & .432 \\
$\mathrm{C}$ & -.397 & -1.865 \\
\hline Notes: & \\
$\mathrm{N}=76(27,38,11)$ & \\
Number of groups $=3$ & \\
Number of independent variables $=10$ & \\
Maximum number of functions $=($ group $\mathrm{n}-1)=2$ \\
Functions 1 \& 2: Square chi =81.153, DF = 22, $\mathrm{p}=.000$ \\
2: Square chi = 33.225, DF $=10, \mathrm{p}=.000$
\end{tabular}

Table 4. Standardized canonical discriminant function coefficients.

\begin{tabular}{llll}
\hline & Episode & $\mathbf{1}$ & $\mathbf{2}$ \\
\hline Contact seeking & 5 & .058 & .557 \\
& 8 & -.452 & .256 \\
Contact maintaining & 5 & -.261 & -.296 \\
& 8 & .469 & -.353 \\
Resistance & 5 & -.095 & -.119 \\
Avoidance & 8 & .218 & -.544 \\
Distance interaction & 5 & .270 & .265 \\
Search attitude during & 8 & .648 & .241 \\
separations & 7 & -.136 & .514 \\
& 5 & -.048 & -.116 \\
\end{tabular}

Table 5. Discriminating structure matrix.

\begin{tabular}{llll}
\hline & & Function & \\
& Episode & $\mathbf{1}$ & $\mathbf{2}$ \\
\hline Avoidance & 8 & $.784\left(^{*}\right)$ & .280 \\
Contact seeking & 8 & $-.560\left(^{*}\right)$ & .066 \\
Avoidance & 5 & $.550\left(^{*}\right)$ & .214 \\
Contact seeking & 5 & $-.453\left(^{*}\right)$ & .064 \\
Contact maintaining & 5 & $-.391\left(^{*}\right)$ & -.375 \\
Search attitude & 7 & $-.388\left(^{*}\right)$ & -.009 \\
during separations & & $-.367\left(^{*}\right)$ & -.278 \\
Contact maintaining & 8 & .106 & $-.631\left(^{*}\right)$ \\
Resistance & 8 & -.146 & $.507\left(^{*}\right)$ \\
Distance interaction & 5 & .045 & $-.388\left(^{*}\right)$ \\
Resistance & 5 & .103 & $.305\left(^{*}\right)$ \\
Distance interaction & 8 & &
\end{tabular}


If we consider the standardized coefficients as they appear in table 4 , the first function is mainly determined by the variable which describes Avoidance behaviors and, in negative, by the variables which codify "contact-seeking" and "contact-maintaining" behaviors, as well as a "search behavior" during separations. High scores in this function are, therefore, associated with high scores in avoidance behaviors towards the caregiver. Conversely, they are associated with low scores in the physical "contact-seeking" and "contact-maintaining" behaviors with the mother and a "search behavior" during separations. The second function, in turn, is characterized by variables which define the "contact-seeking" behavior and the "distance interaction" behavior: in a negative way, the function is characterized by variables which define the "opposition" and "contact-keeping" behaviors.

Now, if we consider the matrix of the discriminant structure (Table 5), that is, the correlations between the scores attributed to the variables and the discriminant functions as they have been identified through the analysis, the first function (avoidant attachment vs. the other two groups) shows a positive correlation with "Avoidance" behaviors (episodes 5 and 8), and a negative correlation with the "contact seeking" and "contact maintaining" variables (episodes 5 and 8 ) as well as with the "search for mother during separations" variable (episode 7). The second function (the other two groups vs. resistant behavior) shows a negative correlation with the "opposition" behaviors (episodes 5 and 8) and a positive correlation with behaviors assessed by the "distance interaction" scale (episodes 5 and 8).

All in all, we can say that the highest discriminant variable between A groups and non-A groups (children with avoidant style vs. the other two groups) is characterized by a strong Avoidance tendency towards the caregiving figure, with only a limited attitude towards searching for the mother or maintaining physical contact with her. In the second instance, the variable which contributes to discriminate between $\mathrm{C}$ groups and non- $\mathrm{C}$ groups (children with resistant style vs. the other two groups) is tied to the activation of "contact-resisting" behaviors, as well as limited "distance interaction" behaviors.

Last, but not least: in order to make a comparison between subjects who had been grouped according to the discriminant analysis classification and subjects classified with the grouping variable, we used a classification method which was based on conditional probabilities and on case distance from group centroids (Graph 2; Table 6). In other words: it is a sort of validation of the discriminant solution by means of a forecast on new subjects, whom we only know the scores of in the independent variables, but not the group they belong to. Through this procedure, it is possible to assign each single case to his/her relevant group, according to his/her probability to belong to one group rather than another: all this means assigning a case to the group whose centroid is at the lowest distance from it.
Once all subjects have been classified, it is possible to make a comparison between the classification generated by the discriminant analysis and the original classification defined by the grouping variable. In this way, it is possible to test the number of subjects who were classified correctly and the ones who were classified wrongly (Barbaranelli, 2006).

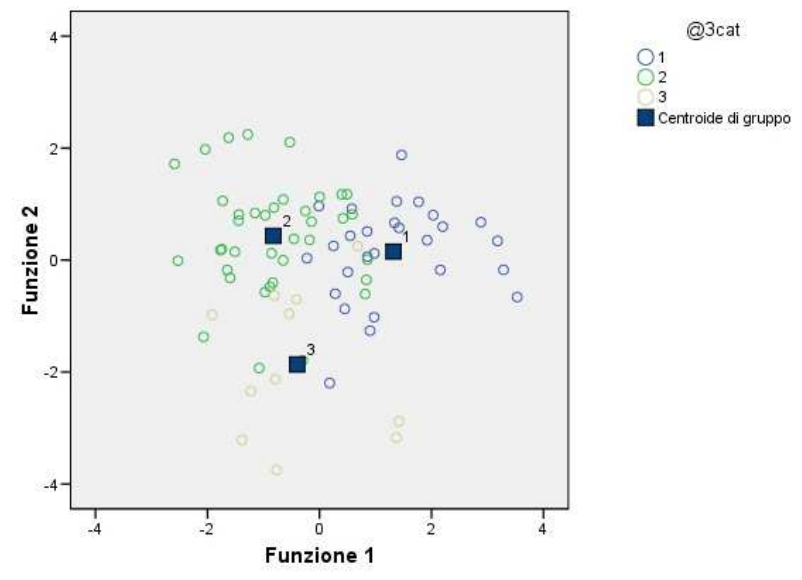

Graph 2. Scatter diagram of unified groups.

Funzione $1=$ Function 1

Funzione 2 = Function 2

Centroide di gruppo $=$ Group centroid

Table 6. Values of the discriminant functions in the group centroids (barycentres).

\begin{tabular}{lll}
\hline \multicolumn{3}{l}{ Functions in the group barycentres } \\
Function
\end{tabular}

Non-standardized canonical, discriminant functions assessed at the group means

Table 7 is the result of the applied procedures: the original classification is crossed with the one deriving from the solution of the discriminant analysis, so as to test its validity, by checking the percentage of cases which were classified correctly by the two procedures. It can be noticed that $79 \%$ of the cases were classified correctly with respect to the original case attribution.

Table 7. Original classification: global results.

\begin{tabular}{llllll}
\hline & \multicolumn{4}{c}{ Foreseen group of assignment } & \multirow{2}{*}{ Total } \\
\hline \multirow{3}{*}{ Calculation } & & A & B & C & \\
& A & 22 & 4 & 1 & 27 \\
& B & 4 & 32 & 2 & 38 \\
& C & 1 & 4 & 6 & 11 \\
& A & 81.5 & 14.8 & 3.7 & 100.00 \\
& B & 10.5 & 84.2 & 5.3 & 100.00 \\
& C & 9.1 & 36.4 & 54.5 & 100.00 \\
\hline
\end{tabular}

$78.9 \%$ of the originally assessed cases classified correctly 


\section{Discussion and Conclusions}

The main goal of our work was to re-test one specific aspect of the Strange Situation coding procedure: the statistical correspondence between the categorical attachment classification system with the ordinal one provided by the scales, which describe the child's behaviors in the various procedure episodes, in order to confirm the results by the original research by Ainsworth et al., (1978).

As for the scales assessing interactive behaviors during the Strange Situation, our data highlight their reliability characteristics when referred to the mother-child interaction, but the same does not apply to the stranger-child interaction. Moreover, our data appear to follow a normal distribution, which seems to testify to the good coherence of this coding system. Furthermore, the application of these scales reliably individuates the child's global attachment pattern, which is assessed according to general descriptive categories. This part of the research and the obtained results strengthen - on the one hand - the intensive use of classifying attachment by means of the patterns' descriptive system: in fact, this system seems to be as refined and exhaustive as the application of micro-analytic scales, which, in general, are certainly more "time-consuming". Therefore, if these data were to be confirmed by other research studies on a more comprehensive number of observations, they would - at least to a certain extent speak for the exclusive use of a classification according to patterns which, in fact, already is the most frequently quoted one in Italian and international research papers using the Strange Situation (see van IJzendoorn et al., 1992) On the other hand, scales that describe children's and adults' discrete behaviors which are tied with the functioning of their attachment system, while also allowing a micro-analytic analysis of the interactions during the procedure, are a very valuable tool in various research and application fields: (a) for complex research data processing, when other competing measures or methods are used to assess children's and/or adults' characteristics which are somehow tied to attachment; (b) when single attachment components and their expressions are taken into careful consideration; (c) when researchers and clinicians need to be trained on how to classify attachment by means of the Strange Situation procedure.

Finally, the results of our research seem to point out some peculiarities of the Italian cultural context with regard to developing attachment: there seems to be a lower degree of security as a distinctive feature of the mother-child relationship. Consequently, further research studies are needed, first of all, in terms of longitudinal research designs offering further indication on the evolution of attachment quality over time within the mother-child dyad. Secondly, greater emphasis should be placed upon the assessment of contextual factors intervening in the attachment formation process: they can have a direct, or else an indirect impact on the child. Among the first ones, we enumerate mother sensitivity and other parents' or child's characteristics (such as temperament), whereas the second ones (which influence the caregiver) include pair relationship quality, family style, perceived social support, the role of other caregiving figures who look after the child when parents are absent (such as, for instance, grandparents or child care providers).

\section{References}

[1] Ainsworth, M. D. S. (1985). Patterns of infant-mother attachment: antecedents and effects on development. Bulletin of the New York Academy of Medicine, 61, 771-791

[2] Ainsworth, M. D. S., Bell, S. M., Stayton, D. J. (1971). Infant-mother attachment and social development: socialization as a product of reciprocal responsiveness to signals. In M. P. M. Richards (Eds), The integration of a child into a social world, Cambridge University Press, London, 99-135

[3] Ainsworth, M. D., Blehar, M., Waters, E., Wall, S. (1978). Patterns of attachment. Hillsdale, NJ: Erlbaum

[4] Ainsworth, M. D. S, Wittig B. A. (1969). Attachment and exploratory behavior of one-year-olds in a strange-situation. In B. M. Foss (Eds), Determinants of infant behavior IV, Methuen, London, 113-136

[5] Barbaranelli C. (2006). Analisi dei dati con SPSS. Le analisi multivariate. LED, Edizioni Universitarie

[6] Bakermans-Kranenburg M. J., Ijzendoorn M H. van (1993). A psychometric study of the Adult Attachment Interview-reliability and discriminant validity. Developmental Psychology, 29, 870-879

[7] Belsky, J., Rovine, M., Taylor, D. G. (1984). The Pennsylvania Infant and Family Development Project, III. The origins of individual differences in infant-mother attachment: Maternal and infant contributions. Child Development, 55, 718-728

[8] Belsky J., Isabella R. A. (1991). Interactional synchrony and the origins of infant-mother attachment: a replication study. Child Development , 62, 373-384

[9] Benoit D., Parker K. C. H. (1994). Stability and Trasmission of Attachment across three Generations. Child Development, $65,1444-1457$

[10] Bowlby J. (1969). Attachment and loss, Vol. 1, Attachment, Hogarth Press, London

[11] Bowlby J. (1973). Attachment and loss, Vol. 2, Separation, anxiety and anger, Hogarth Press, London

[12] Bowlby J. (1980). Attachment and loss, vol. 3, Loss, sadness and depression, Hogarth Press, London

[13] De Wolff M. S., Ijzendoorn M. H. Van (1997). Sensitivity and attachment: a meta-analysis on parental antecedents of infants attachment, Child Development, 68, 571-591

[14] Goldsmith H. H., Alansky J. A. (1987). Maternal and infant predictors of attachment: A meta-analytic review, Journal of Clinical and Consulting Psychology, 55, 805-816

[15] Isabella R. A. (1993). Origins of attachment: maternal interactive behavior across the first year. Child Development, $64,605-621$ 
[16] Main M., Solomon J. (1986). Discovery of a new, insecure-disorganized-disoriented attachment pattern. In: Brazelton T.B., Yogman M. (Eds) Affective development in infancy. Ablex, Norwood

[17] Main M., Solomon J. (1990). Procedures for identifying infants as disorganized-disoriented during Ainsworth Strange Situation. In: Greenberg M. T., Cicchetti A., Cummings M. E. (Eds) Attachment in the preschool years. Theory, research and intervention. The University of Chicago Press, Chicago

[18] Main, M., Weston, D. (1981). Quality of attachment to mother and to father: related to conflict behaviour and the readiness for establishing new relationships, Child Development, 52, 932-940

[19] Meins E. (1997). Security of Attachment and the Social Development of Cognition, Psychology Press, Hove

[20] Schneider-Rosen K., Rothbaum P. (1993). Quality of Parental Caregiving and Security of Attachment, Developmental Psychology, 29, $358-367$

[21] Seifer R., Shiller M., Sameroff A. J., Resnik S., Riordan K., (1996). Attachment, maternal sensitivity and infant temperament during the first year of life, Developmental Psychology, 32, 1, 12-25

[22] Simonelli A., De Palo F., Moretti M., Merlin Baratter P., Porreca A. (2014). The Strange Situation Procedure: the role of the attachment patterns in the italian culture, American Journal of Applied Psychology, in press

[23] Smith, P. B., Pederson, D. R. (1988). Maternal sensitivity and patterns of infant-mother attachment. Child Development, 59, 4, 1097-1101
[24] Solomon J., George C. (2002). Attaccamento e accudimento: il sistema comportamentale di accudimento. In J. Cassidy, P. R. Shaver (Eds.), Manuale dell'attaccamento. Roma, Fioriti Editore, $737-760$

[25] Thompson R. A. (2002). Attaccamento infantile e sviluppo successivo. In J. Cassidy, P. R. Shaver (Eds), Manuale dell'attaccamento, Fioriti Editore, Roma, 807-830

[26] Van Ijzendoorn M. H., Bakermans-Kranenburg M. (2005). Sensibilità materna e temperamento infantile nella formazione del legame di attaccamento. In Cassibba R., van IJzendoorn M. H. (Eds), L'intervento basato sull'attaccamento, Il Mulino: Bologna

[27] Van Ijzendoorn M. H., Dijkstra J., Bus A. G. (1995). Attachment, intelligence and language: a meta-analysis, Social Development, 4, 115-128

[28] Van Ijzendoorn M. H., Goldberg S., Kroonenberg P. M., Frenkel O. J. (1992). The relative effects of maternal and child problems on the quality of attachment: a meta-analysis of attachment in clinical samples, Child Development , 63, $840-858$

[29] Van Ijzendoorn M. H., Sagi A. (2002). Modelli trans-culturali di attaccamento: dimensioni universali e contestuali. In Cassidy J., Shaver P. R., Manuale dell'attaccamento, Fioriti Editore, Roma, 807-830

[30] Waters E. (1979). The reliability and Stability of Individual Differences in Infant-Mother Attachment, Child Development, 49, 971-5

[31] Weinfield N. S., Sroufe A., Egeland B., Carlson E. A. (2002) La natura delle differenze individuali nell'attaccamento del bambino al caregiver. In J. Cassidy, P. R. Shaver, Manuale dell'attaccamento, Fioriti Editore, Roma, 78-100. 